\title{
Thromboelastometric assessment of hemostasis following hydroxyethyl starch (130/0.4) administration as a constant rate infusion in hypoalbuminemic dogs
}

Angelica Botto ${ }^{1}$, Barbara Bruno ${ }^{1}$, Cristiana Maurella ${ }^{2}$, Fulvio Riondato ${ }^{1}$, Alberto Tarducci ${ }^{1}$, Giulio Mengozzi ${ }^{3}$ and Antonio Borrelli ${ }^{1^{*}}$

\begin{abstract}
Background: The primary aim was to evaluate by means of thromboelastometry (ROTEM) the effects of hydroxyethyl starch (HES) 130/0.4 administered as a constant rate infusion (CRI) on hemostasis in hypoalbuminemic dogs. The second aim was to use ROTEM analysis to detect whether all hypoalbuminemic dogs of our population were hypercoagulable.

Results: The study sample was 20 hypoalbuminemic dogs (albumin $<2 \mathrm{~g} / \mathrm{dl}$ ) with normal perfusion parameters and requiring intravenous fluid therapy. In order to support plasma colloid osmotic pressure, in addition to crystalloid, HES 130/0.4 was administered as a constant rate infusion at $1 \mathrm{ml} / \mathrm{kg} / \mathrm{h}$ (group $1, n=11$ ) or $2 \mathrm{ml} / \mathrm{kg} / \mathrm{h}$ for $24 \mathrm{~h}$ (group $2, n=9$ ). Blood samples were collected at baseline (T0) and $24 \mathrm{~h}$ postinfusion ( $\mathrm{T} 1$ ); coagulation was assessed by standard coagulation profile (prothrombin time, activated partial thromboplastin time, and fibrinogen), and ROTEM analysis (in-TEM ${ }^{\oplus}$, ex-TEM ${ }^{\circledast}$ and fib- TEM ${ }^{\oplus}$ profile).

No statistically significant differences in ROTEM values in group 1 were observed $(P>0.05)$, whereas in group 2 statistically significant differences $(P<0.05)$ were found at $\mathrm{T} 1$ in the in-TEM ${ }^{\oplus}$ profile [decrease in clot formation time $(P=0.04)$ and increase in a angle $(P=0.02)$ ] and in the ex-TEM ${ }^{\circledR}$ profile [increase in maximum clot firmness $(P=0.008)$ and a angle $(P=0.01)$; no changes were identified in the fib-TEM ${ }^{\oplus}$ profile. In both groups, a statistically significant decrease $(P=0.007)$ in hematocrit was noted, whereas no statistically significant differences in platelet count and standard coagulation profile were found. In group 2 , a statistically significant increase in TS values $(P=0.03)$ was noted at T1. ROTEM tracings indicating a hypercoagulable state were observed in 7/20 dogs at T0 (5/11 in group 1 and 2/9 in the group 2).
\end{abstract}

Conclusion: Our findings suggest that HES 130/0.4 administered as CRI does not cause hypocoagulability in hypoalbuminemic dogs. A trend toward hypercoagulability, probably related to the underlying diseases, was observed in group 2 at T1.

Although all dogs were hyoalbuminemic, only $7 / 20$ were hypercoagulable at T0, confirming the lack of correlation between albumin level and prothrombotic state.

Keywords: Dogs, Hydroxyethyl starch, Hypoalbuminemia, Thromboelastometry

\footnotetext{
*Correspondence: antonio.borrelli@unito.it

'Department of Veterinary Science, University of Turin, Largo Paolo Braccini $n$

²-5, 10095 Grugliasco, TO, Italy

Full list of author information is available at the end of the article
} 


\section{Background}

Hydroxyethyl starch (HES) comprises a group of synthetic polymers routinely used in veterinary anesthesia and critical care medicine to maintain blood volume, counteract anesthesia-induced hypotension, to resuscitate patients with hypovolemic shock or sepsis, and to support intravascular colloid osmotic pressure (COP) during hypoalbuminemic states $[1,2]$. HES can be administered as a bolus or as a constant rate infusion (CRI) typically at a rate of $20-50 \mathrm{ml} / \mathrm{Kg} /$ day and $1-2 \mathrm{ml} / \mathrm{kg} / \mathrm{h}$, respectively [1-3], the doses are generally extrapolated from human literature $[1,2]$. The physicochemical and pharmacological properties of HES, as well as its classification, depend on their mean molecular weight (MW), molar substitution (MS), and C2/C6 ratio [4]. The rate of degradation and elimination of HES depends on the MS and $\mathrm{C} 2 / \mathrm{C} 6$ ratio, whit higher MS and C2/C6 ratio leading to a slower elimination and greater intravascular retention time and associated side effects [5]. To improve safety and pharmacological properties, newer third-generation starch products with reduced MW and MS have been developed [4] that have shorter half-life, improved pharmacokinetic and pharmacodynamic properties, and fewer side effects [6]. Nonetheless, controversy in human medicine and veterinary medicine persists concerning the safety of HES. Indeed, recent reports of side effects in people (e.g., acute kidney injury, tissue storage, and impaired primary and secondary hemostasis), led to a temporary suspension of HES products. Authorization was reinstated about a year later, together with new guidelines for contraindications in certain conditions (e.g., sepsis) [2].

Hypocoagulability and increased risk of bleeding after administration of HES in human patients is believed to be due to hemodilution and direct effects of HES on the hemostatic system. Plasma accumulation of starch macromolecules can lead to platelet dysfunction, decreasing expression and activation of the surface receptor GPIIb/ IIIa, decreased concentration of circulating von Willebrand factor (vWf) and factor VIII, impaired factor XIII fibrin cross-linking, and enhanced fibrinolysis resulting in a weaker and smaller clot $[4,7]$.

In veterinary medicine, both in vitro [8-14] and in vivo [15-20] studies have demonstrated impairment of whole blood coagulation after the administration of HES. After blood dilution with both crystalloids and colloids, in vitro studies have found a dose-dependent decrease in platelet function, an increase in prothrombin time (PT) and partial activated thromboplastin time (aPTT), and changes in viscoelastic parameters toward hypocoagulability (thromboelastometry or thromboelastography), with more severe impairment observed after dilution with HES [8-14]. Three in vivo studies have assessed only platelet function, whereas others studies have evaluated secondary hemostasis or whole blood coagulation following bolus administration of HES (doses ranging from 10 to $40 \mathrm{ml} / \mathrm{kg}$ in approximately $30 \mathrm{~min}$ ), demonstrating hypocoagulability in healthy dogs or dogs affected by experimentally induced disease [15-20].

Viscoelastic techniques, such as thromboelastometric analysis (ROTEM), evaluate coagulation in whole blood samples. Since they take into account plasmatic and cellular elements, they better reflect the cell-based model of hemostasis, that describes coagulation as a dynamic process in which plasmatic coagulation factors interact with the cell surface $[21,22]$. Rotational thromboelastometry use several reagents in different profiles to measure the kinetics of clot formation (time required for clot formation), the mechanical properties (clot strength), and the time required for clot dissolution (fibrinolysis) $[22,23]$. It is the most useful tool to assess the presence of a hypercoagulable state, as compared with standard coagulation assays (PT, aPTT, fibrin degradation products and D-dimers) [22, 23].

To date, there are no published studies investigating the effects of HES 130/0.4 on whole blood hemostasis after its administration as a CRI in dogs with naturally occurring disease. Hypoalbuminemic dogs are a type of patients in which natural or synthetic colloids are frequently used to support the COP. These patients have also a high risk to form venous and arterial thrombi, and some studies have identified by means of ROTEM or thromboelastography (ROTEG) a hypercoagulable condition in dogs with protein losing enteropathy (PLE) or nephropathy (PLN) [24-27]. The hypothesized mechanism at baseline of this prothrombotic condition is a loss of proteins (from the kidney or the gut), which implies the loss of anticoagulant factors such as antithrombin [28-30]. In human medicine multiple mechanisms are involved in the development of hypercoagulability in case of hypoalbuminemia, including spontaneous platelet aggregation, increase in coagulation factors, hypofibrinolysis, decrease in antithrombin and protein $\mathrm{C}$ [31, 32].

The first aim of the present study was therefore to evaluate the effects of HES 130/0.4 administered as a CRI (at dose of $1 \mathrm{ml} / \mathrm{Kg} / \mathrm{h}$ and $2 \mathrm{ml} / \mathrm{Kg} / \mathrm{h}$ ) on hemostasis in hypoalbuminemic dogs, by means of ROTEM. The hypothesis was that HES administration will cause a hypocoagulability state.

The second aim was to determine how many hypoalbuminemic dogs were hypercoagulable at presentation.

\section{Methods}

This randomized, clinical prospective trial was performed on client-owned dogs. The protocol was approved by the Bioethics Committee of the author's 
University. The dog owners were informed about the methods and aims of the study and gave their written informed consent.

\section{Animals and study design}

The dogs were selected from patients admitted to our Veterinary Teaching Hospital for hospitalization. The inclusion criteria were: hypoalbuminemia (albumin $<2 \mathrm{~g} / \mathrm{dl}$ ) regardless of underlying disease, normal perfusion parameters, to require intravenous fluid therapy due to their underlying disease (e.g., increased losses, anorexia, dehydration). All dogs underwent complete physical examination and perfusion parameters were assessed by clinical evaluation and non-invasive measurement of arterial blood pressure using Doppler (Model 811-B, Parks Medical Electronics Inc., Oregon, USA). Exclusion criteria were pulmonary disease, cardiac and liver failure, renal azotemia, pre-existing hypocoagulability, and history of non-steroidal anti-inflammatory drugs, steroidal drugs, artificial colloid or blood products administration in the 4 weeks prior to the study. Additional exclusion criteria were abnormal perfusion parameters (heart rate $>130 \mathrm{bpm}$, poor pulse quality, capillary refill time $>2 \mathrm{~s}$ or $<1 \mathrm{~s}$, systolic blood pressure $<90 \mathrm{mmHg}$ and venous lactate $>2 \mathrm{mmol} / \mathrm{L}$ ) and serologic test positive to Ehrlichia canis, Dirofilaria immitis, Borrelia burgdorferi, Anaplasma phagocytophilum, Anaplasma platys and/or Leishmania infantum.

Blood samples were collected by atraumatic venipuncture of the jugular vein with a 20 -gauge needle using minimum stasis. Samples that were difficult to obtain (e.g., venipuncture required numerous attempts, needle repositioning or interruption of blood flow into the tube) were discarded and blood collection was repeated from the contralateral jugular vein. After blood collection, cell blood count (CBC) (ADVIA 120 Hematology, Siemens Healthcare Diagnostics, Tarrytown, NY, USA), serum concentration of albumin (ILAB 300 plus, Clinical Chemistry System, Instrumentation Laboratories, Milan, Italy), total solid and packed cell volume were measured according to the study protocol. Other specific analyses were performed to assess the cause of hypoalbuminemia, as needed on a case-by-case basis.

Coagulation was assessed by standard coagulation profile [prothrombin time (PT), activated partial thromboplastin time (aPTT), and fibrinogen] (Coagulometer StART, Diagnostica Stago, Parsippany, NJ, USA), and by ROTEM analysis, (ROTEM ${ }^{\circ}$, TEM Innovations $\mathrm{GmbH}$, Munich, Germany) for evaluating in-TEM ${ }^{\circ}$, ex-TEM ${ }^{\circ}$, and fib-TEM ${ }^{\circ}$ profiles. Blood samples were divided into two tubes containing 3.2\% buffered sodium citrate (Vacumed 3.2\% buffered sodium citrate, FL Medical, Torreglia, Italy).
Thromboelastometric analyses were performed according to PROVETS guidelines [33, 34], and the analyses run for $60 \mathrm{~min}$. For each blood sample, three thromboelastometric profiles were performed: in-TEM ${ }^{\circ}$, ex-TEM ${ }^{\circ}$, and fib-TEM ${ }^{\circ}$ assay to evaluate the intrinsic and the extrinsic pathway, respectively, and assess the functional fibrinogen contribution to clot formation. For the in-TEM ${ }^{\circ}$ profile, the blood sample was recalcified using the start-TEM ${ }^{\circ}$ reagent and coagulation was activated with the specific reagent containing ellagic acid, whereas the ex-TEM ${ }^{\circ}$ profile was activated by adding thromboplastin after recalcification. To obtain the fib-TEM ${ }^{\ominus}$ profile, coagulation was activated using thromboplastin in addition to a specific reagent containing a platelet inhibitor (cytochalasin D). The following variables were assessed for each profile: clotting time ([CT], s); clot formation time [(CFT) s]; maximum clot firmness $[(\mathrm{MCF})] \mathrm{mm}]$; and $\alpha$ angle $\left(\alpha,{ }^{\circ}\right)$. Clotting time describes the time in seconds from clot initiation until the fibrin polymers are produced and the amplitude reaches $2 \mathrm{~mm}$; this parameter is dependent on the concentration and activity of plasma coagulation factors [23]. Clot formation time, measured in seconds, is the time from initiation of clotting $(2 \mathrm{~mm})$ until an amplitude of $20 \mathrm{~mm}$ is reached [23]. Clot formation time and $\alpha$ angle provide information about the kinetics of clot formation and are predominantly affected by platelet count and function and fibrinogen concentration [23]. Maximum clot firmness represents the maximum amplitude reached by the clot, reflects maximal clot strength and stability, and is affected by fibrinogen, platelet count and function (except in the fib-TEM ${ }^{\circ}$ profile where platelet are inhibited), thrombin, FXIII, and hematocrit (Hct) [23]. Additional calculated parameter is platelet contribution to maximum clot elasticity (MCE platelet), which evaluates the platelet component to clot strength and is obtained as follows: $\mathrm{MCE}_{\text {platelet }}=\mathrm{MCE}_{\text {extem }}{ }^{-}$ $\mathrm{MCE}_{\text {fibtem }}[\mathrm{MCE}=(\mathrm{MCF} * 100) /(100-\mathrm{MCF})]$ [35].

A ROTEM tracing indicating hypocoagulability is characterized by an increase in CT and CFT and a decrease in MCF and $\alpha$ angle, whereas a ROTEM tracing indicating hypercoagulability is characterized by a decrease in CT and CFT and an increase in MCF and $\alpha$ angle. ROTEM tracings were considered abnormal when more than one ROTEM value was above ( $\alpha$ angle, MCF) or below (CT, CFT) our reference ranges (Table 1).

Serological tests for Ehrlichia canis, Dirofilaria immitis, Borrelia burgdorferi, Anaplasma phagocytophilum, Anaplasma platys (Snap 4DX, IDEXX Laboratories, Westbrook, ME) and Leishmania infantum (Snap Leishmania, IDEXX Laboratories, Westbrook, ME) were also carried out.

An intravenous catheter was inserted into the peripheral vein, and fluid therapy was started using lactated 
Table 1 ROTEM and standard coagulation profiles results, before and $24 \mathrm{~h}$ after hydroxyethyl starch 130/0.4 infusion

\begin{tabular}{|c|c|c|c|c|c|}
\hline \multirow[b]{2}{*}{ ROTEM } & \multicolumn{2}{|c|}{ GROUP $1(1 \mathrm{ml} / \mathrm{kg} / \mathrm{h}) \mathrm{N}=11$} & \multicolumn{2}{|c|}{ GROUP $2(2 \mathrm{ml} / \mathrm{kg} / \mathrm{h}) \mathrm{N}=9$} & \multirow[t]{2}{*}{ Institutional reference ranges } \\
\hline & T0 & $\mathrm{T} 1$ & T0 & $\mathrm{T} 1$ & \\
\hline \multicolumn{6}{|l|}{ In-TEM ${ }^{\circledast}$} \\
\hline$C T(s)$ & $180(132-268)$ & $166(61-209)$ & $188(112-279)$ & $141(108-240)$ & $126-363 s$ \\
\hline CFT (s) & $63(45-132)$ & $59(41-113)$ & $73(41-86)$ & $58 *(38-81)$ & $47-224 s$ \\
\hline $\mathrm{MCF}(\mathrm{mm})$ & $72(56-80)$ & $72(58-88)$ & $68(62-77)$ & $72(62-78)$ & $50-75 \mathrm{~mm}$ \\
\hline a angle $\left({ }^{\circ}\right)$ & $77(65-81)$ & $79(69-82)$ & $76(73-82)$ & $78 *(74-82)$ & $55-81^{\circ}$ \\
\hline \multicolumn{6}{|l|}{ Ex-TEM ${ }^{\circledast}$} \\
\hline $\mathrm{CT}(\mathrm{s})$ & $44(27-61)$ & $45(20-77)$ & $46(30-89)$ & $40(33-80)$ & $29-92 \mathrm{~s}$ \\
\hline CFT (s) & $67(38-159)$ & $78(49-132)$ & $81(51-96)$ & $62(49-92)$ & $54-275 \mathrm{~s}$ \\
\hline MCF (mm) & $77(60-82)$ & $70(64-83)$ & $70(66-81)$ & $72 *(67-86)$ & $36-73 \mathrm{~mm}$ \\
\hline a angle $\left(^{\circ}\right)$ & 76 (61-83) & $76(65-82)$ & $74(71-80)$ & $77 *(73-81)$ & $47-79^{\circ}$ \\
\hline \multicolumn{6}{|l|}{ Fib-TEM $^{\oplus}$} \\
\hline $\mathrm{CT}(\mathrm{s})$ & $47(31-107)$ & $39(21-57)$ & $45(29-92)$ & $39(32-80)$ & $14-102$ s \\
\hline $\mathrm{MCF}(\mathrm{mm})$ & $25(7-38)$ & $16(8-46)$ & $15(9-30)$ & $20(14-78)$ & $6-26 \mathrm{~mm}$ \\
\hline a angle $\left(^{\circ}\right)$ & $77,5(70-86)$ & $76(30-86)$ & $76,5(67-81)$ & $77(71-84)$ & $40-78^{\circ}$ \\
\hline MCE $E_{\text {platelet }}$ & $294(142-404)$ & $211(169-441)$ & $206(175-383)$ & $235(183-571)$ & $50-235$ \\
\hline \multicolumn{6}{|l|}{ Standard coagulation } \\
\hline aPTT (s) & $12.5(9.6-15.4)$ & $12.3(8.7-16)$ & $13.9(12.1-16)$ & $14.5(11.7-16)$ & $12-16 s$ \\
\hline PT (s) & $7.5(6.6-9.6)$ & 7.15 (6.6-9.9) & $7.4(6.2-10)$ & $7.3(6.3-10)$ & $8-10 \mathrm{~s}$ \\
\hline Fibrinogen ( $g / L)$ & $3.5(2.5-8.5)$ & $3.6(2.4-7.9)$ & $3.4(2.2-7.4)$ & $4.1(2.2-7.1)$ & $1.5-4.50(\mathrm{~g} / \mathrm{L})$ \\
\hline
\end{tabular}

Values are expressed as median (minimum-maximum)

Values of institutional reference ranges for ROTEM parameters are expressed as $95 \%$ confidence intervals ${ }^{14}$

In-TEM ${ }^{\circledast}$ intrinsic thromboelastometry pathway, Ex-TEM ${ }^{\oplus}$ extrinsic thromboelastometry pathway, Fib-TEM ${ }^{\circledast}$ functional fibrinogen, $C T$ clotting time, CFT clot formation time, MCF maximum clot firmness, $P T$ prothrombin time, $A P T T$ activated partial thromboplastin time

* Indicates statistically significant differences between T0 and T1 $(P<0.05)$

Ringer's solution (Ringer's lactate solution, Baxter S.p.A, Rome, Italy), to replace dehydration, maintenance, and ongoing losses, and HES 130/0.4 [Voluven, Fresenius Kabi Italia srl., Isola della Scala (VR), Italy] for COP support. Hydroxyethyl starch 130/0.4 was administered as a CRI for at least $24 \mathrm{~h}$. Colloid treatment $[1 \mathrm{ml} / \mathrm{kg} / \mathrm{h}$ (group 1) or $2 \mathrm{ml} / \mathrm{kg} / \mathrm{h}$ (group 2)] was randomly assigned via a computer-generated program (Microsoft Excel, Redmond, WA, USA). The dogs were assessed for body temperature, respiratory rate and perfusion parameters every $4 \mathrm{~h}$. Blood samples were collected at baseline (T0), to assess all previously laboratory analysis described, and $24 \mathrm{~h}$ after start of infusion (T1) CBC, albumin, packed cell volume, total solid (TS), and coagulation tests were repeated.

\section{Statistical analysis}

Data were collected and analyzed with the software Stata 14.2 (Stata Statistical Software, release 10, StataCorp LP, College Station, TX, USA). Normality of data was assessed using the Shapiro-Wilk test.

To evaluate changes in ROTEM parameters after administration of the two different doses of HES 130/0.4 (CRI of 1 and $2 \mathrm{ml} / \mathrm{kg} / \mathrm{h}$ ) at two time points (T0 vs. T1), a hierarchical linear mixed effects model was used, where the random effect is given by the individual subject. Bonferroni correction was applied to detect in which medium the difference was statistically significant. When the data did not meet the assumption of normality, the comparison was conducted with the sign test.

Analysis of the data showed that only some dogs were hypercoagulable and that many had been randomly assigned to group 1. Despite the small number of hypercoagulable animals, Friedman's test was carried out and the population divided (independent of HES dose administered) into two subgroups: hypercoagulable dogs (group $\mathrm{H}$ ) and not hypercoagulable dogs (group $\mathrm{NH}$ ). This was done to detect differences in ROTEM parameters at the two time points (T0 vs. T1).

A value of $P<0.05$ was considered significant.

\section{Results}

Of the total of 25 adult dogs initially enrolled, 5 were excluded because of Leishmaniosis $(n=2)$, liver failure $(n=2)$, and hypocoagulability with an abnormal thromboelastometric tracing at T0 $(n=1)$. The study sample comprised 20 dogs: 11 received HES 130/0.4 as a CRI at $1 \mathrm{ml} / \mathrm{kg} / \mathrm{h}$ (group 1) and 9 at $2 \mathrm{ml} / \mathrm{kg} / \mathrm{h}$ (group 2) for at 
least $24 \mathrm{~h}$. In group 1 , the median age was 7 years ( $\mathrm{min}$ 2-max 12) and the median body weight $27 \mathrm{~kg}(\min 5$ max 39); breeds included: Australian Shepherd $(n=1)$, Border Collie $(n=1)$, Rottweiler $(n=1)$, German Shepherd $(n=1)$, Beagle $(n=1)$, and mixed breed $(n=6)$. Seven were females ( 4 neutered and 3 intact) and 4 males ( 1 castrated and 3 intact). Dogs included were affected by acute protein losing enteropathy $(n=4)$, chronic protein losing enteropathy $(n=3)$, protein losing nephropathy (PLN) $(n=1)$, or chylothorax $(n=3)$.

In group 2 , the median age was 7 years $(\min 2-\max$ $10)$ and the median body weight $17.8 \mathrm{~kg}$ (min $5-\max$ 44); breeds included: Rottweiler $(n=1)$, English Bulldog $(n=1)$, Pit bull $(n=1)$, longhaired Dachshund $(n=1)$, Labrador $(n=1)$, Jack Russell $(n=2)$, and mixed breed $(n=2)$. Six were females (4 neutered and 2 intact) and 3 intact males. Dogs included were affected by chronic protein losing enteropathy $(n=6)$, chylothorax $(n=2)$ or hypoadrenocorticism $(n=1)$.

There were no statistically significant differences in age, body weight, serum albumin concentration, ROTEM values, PT and fibrinogen concentration between the two groups at baseline (T0). The aPTT was slightly prolonged in group 2 at both T0 and T1 $(\beta=2.2$, C.I. $95 \%$ and $P=0.027$, respectively), but still within the reference range.

Comparison between PT, aPTT, and fibrinogen concentration showed no statistically significant withingroup differences between the two time points ( $\mathrm{T} 0$ versus T1) (Table 1). While no statistically significant within-group differences in ROTEM values (T0 vs. T1) were found in group 1; statistically significant differences were noted in group 2 at T1: a decrease in CFT $(P=$ $0.04)$ and an increase in the $\alpha$ angle $(P=0.02)$ in the inTEM $^{\bullet}$ profile and an increase in MCF $(P=0.008)$ and the $\alpha$ angle $(P=0.01)$ in the ex-TEM ${ }^{\circ}$ profile (Table 1$)$, whereas no changes was identified in the fib-TEM ${ }^{\circ}$ profile and in the $\mathrm{MCE}_{\text {platelet. Nevertheless, there were no }}$ statistically significant differences in ROTEM parameters between the two groups at T1. In both groups, there was a statistically significant decrease in Hct $(P=0.007)$ at T1 (time-dependent reduction), but no statistically significant dose-dependent difference between the two dosages (Table 2). There was no statistically significant difference in platelet count at T1 in either group (Table 2). Finally, a statistically significant increase in TS values $(P=0.03)$ in group 2 was noted at T1, but no statistically significant differences in albumin concentration in either group (Table 2).

ROTEM tracings indicating a hypercoagulable state were observed in 7/20 dogs at T0 (5/11 in group 1 and $2 / 9$ in group 2 ). (Table 3 ) There were no statistically significant changes from $\mathrm{T} 0$ to $\mathrm{T} 1$ in either subgroup $\mathrm{H}$ or subgroup NH. Analysis of single animals classified as hypercoagulable (subgroup $\mathrm{H}$ ) showed that the fibrinogen level was outside normal limits in 6/7 dogs (median 6.02, min 3.20 and $\max 8.53$ ), whereas all the dogs classified as not hypercoagulable (subgroup $\mathrm{NH}$ ) had levels within the normal range (median 3.26, min 2.23 and max 4.43) (Table 3). In addition, the $\mathrm{MCE}_{\text {platelet }}$ was outside the normal range in all the hypercoagulable dogs (median 339, min 257 and max 404) and it was increased only in $3 / 13$ classified as not hypercoagulable (median 205, min 142 and max 316) (Table 3).

\section{Discussion}

The main finding of the present study was that a hypocoagulable state was not observed by either 1 or $2 \mathrm{ml} /$ $\mathrm{kg} / \mathrm{h}$ of HES 130/0.4 in dogs with hypoalbuminemia. In contrast to our hypothesis, ROTEM analysis at T1 revealed statistically significant differences in some parameters consistent with a trend toward a hypercoagulability state after CRI at $2 \mathrm{ml} / \mathrm{kg} / \mathrm{h}$. In particular, in the in$\mathrm{TEM}^{\circ}$ profile a decrease in CFT and an increase in $\alpha$ angle, and in the ex-TEM ${ }^{\circ}$ profile an increase in both $\alpha$ angle and MCF was found (Table 1). No statistical significant differences were shown comparing the ROTEM values of group 1 and group 2 at T1, then we can exclude that these variations have been induced by the different dose used in the group 2, and affirm that the change could be time dependent. As the dogs in this study presented with various different diseases, it is possible that an inflammatory state in the group 2 progressed during the $24 \mathrm{~h}$ of observation from $\mathrm{T} 0$ to $\mathrm{T} 1$ and affected coagulation in a different way. Since there

Table 2 Results of laboratory parameters, before and $24 \mathrm{~h}$ after hydroxyethyl starch 130/0.4 infusion

\begin{tabular}{|c|c|c|c|c|}
\hline & \multicolumn{2}{|c|}{ GROUP $1(1 \mathrm{ml} / \mathrm{kg} / \mathrm{h}) \mathrm{N}=11$} & \multicolumn{2}{|c|}{ GROUP $2(2 \mathrm{ml} / \mathrm{kg} / \mathrm{h}) \mathrm{N}=9$} \\
\hline & T0 & $\mathrm{T} 1$ & T0 & $\mathrm{T} 1$ \\
\hline Hematocrit (\%) & $40(29-54)$ & $39 *(25-53)$ & $38(25-50)$ & $35 *(25-55)$ \\
\hline Platelet count (x $10 \mathrm{E} 09$ cell/L) & $366(156-853)$ & $340(145-800)$ & $397(125-641)$ & $422(134-731)$ \\
\hline Total Solid (g/L) & $0.36(0.3-0.55)$ & $0.36(0.25-0.54)$ & $0.32(0.25-0.5)$ & $0.35 *(0.27-0.5)$ \\
\hline Albumin $(\mathrm{g} / \mathrm{L})$ & $0.16(0.12-0.19)$ & $0.16(0.11-0.24)$ & $0.15(0.13-0.18)$ & $0.14(0.11-0.22)$ \\
\hline
\end{tabular}

Values are expressed as median (minimum-maximum)

*Indicates statistically significant differences between T0 and T1 $(P<0.05)$ 
Table 3 ROTEM results at baseline $(N=20)$

\begin{tabular}{|c|c|c|c|c|c|c|c|c|c|c|c|c|c|c|}
\hline \multirow{2}{*}{$\frac{\mathrm{T0}}{\mathrm{G} 1(\mathrm{~N}=11)}$} & \multicolumn{4}{|c|}{ In-TEM ${ }^{\circledast}$} & \multicolumn{4}{|c|}{ Ex-TEM $^{\circledR}$} & \multicolumn{6}{|c|}{ Fib-TEM $^{\circledR}$} \\
\hline & $C T$ & CFT & MCF & a angle & $C T$ & CFT & MCF & $a$ angle & $C T$ & MCF & $a$ angle & MCE platelet & Fib & Disease \\
\hline Dog 1 & 216 & 85 & 72 & 73 & 43 & 56 & 80 & 80 & 107 & 38 & 73 & 339 & 3.2 & APLE \\
\hline $\operatorname{Dog} 2$ & 132 & 104 & 75 & 73 & 43 & 159 & 64 & 61 & 56 & 119 & 25 & 144 & 3.5 & APLE \\
\hline Dog 3 & 142 & 54 & 70 & 79 & 39 & 67 & 69 & 76 & 45 & 11 & 70 & 210 & 3.2 & CPLE \\
\hline Dog 4 & 144 & 52 & 70 & 80 & 27 & 74 & 67 & 75 & 31 & 13 & 73 & 188 & 2.7 & CPLE \\
\hline Dog 5 & 180 & 132 & 56 & 65 & 61 & 143 & 60 & 62 & 51 & 7 & ND & 142 & 3.5 & APLE \\
\hline Dog 6 & 180 & 45 & 75 & 81 & 41 & 38 & 79 & 83 & 38 & 34 & 86 & 325 & 6.2 & PLN \\
\hline $\operatorname{Dog} 7$ & 156 & 47 & 80 & 80 & 53 & 66 & 81 & 79 & 50 & 28 & 83 & 387 & 6 & CPLE \\
\hline Dog 8 & 163 & 63 & 75 & 77 & 44 & 83 & 77 & 75 & 41 & 16 & 78 & 316 & 4.4 & $\mathrm{CH}$ \\
\hline Dog 9 & 241 & 50 & 79 & 80 & 61 & 47 & 82 & 81 & 54 & 34 & 79 & 404 & 8.5 & $\mathrm{CH}$ \\
\hline Dog 10 & 268 & 103 & 62 & 69 & 48 & 107 & 68 & 74 & 47 & 14 & 77 & 196 & 3.3 & CPLE \\
\hline Dog 11 & 184 & 66 & 70 & 76 & 46 & 60 & 77 & 78 & 37 & 29 & 80 & 294 & 5.3 & APLE \\
\hline \multicolumn{15}{|l|}{$\mathrm{G} 2(N=9)$} \\
\hline Dog 12 & 241 & 52 & 77 & 79 & 46 & 51 & 82 & 80 & 45 & 30 & 80 & 383 & 7.4 & CPLE \\
\hline Dog 13 & 279 & 86 & 68 & 73 & 48 & 82 & 69 & 73 & 46 & 14 & 67 & 206 & 2.2 & CPLE \\
\hline Dog 14 & 198 & 79 & 67 & 74 & 40 & 96 & 67 & 71 & 36 & 22 & 79 & 175 & 4.2 & CPLE \\
\hline Dog 15 & 196 & 51 & 71 & 79 & 43 & 60 & 73 & 78 & 46 & 15 & 76 & 253 & 2.7 & CPLE \\
\hline Dog 16 & 119 & 41 & 72 & 82 & 30 & 57 & 75 & 79 & 29 & 30 & 81 & 257 & 4.6 & $\mathrm{CH}$ \\
\hline Dog 17 & 188 & 73 & 67 & 75 & 59 & 89 & 69 & 73 & 60 & 15 & 75 & 205 & 3.5 & $\mathrm{CH}$ \\
\hline Dog 18 & 151 & 75 & 64 & 76 & 38 & 72 & 70 & 75 & 38 & 22 & 77 & 205 & 2.8 & CPLE \\
\hline Dog 19 & 112 & 57 & 73 & 78 & 56 & 81 & 73 & 74 & 31 & 9 & ND & 260 & 2.4 & $A D$ \\
\hline Dog 20 & 133 & 80 & 62 & 74 & 89 & 86 & 66 & 73 & 92 & 14 & 69 & 178 & 3.4 & CPLE \\
\hline
\end{tabular}

G 1 Group 1 (1 ml/kg/h), G 2 Group 2 (2 ml/kg /h), In-TEM ${ }^{\circledast}$ intrinsic thromboelastometry pathway, Ex-TEM ${ }^{\circledast}$ extrinsic thromboelastometry pathway, Fib-TEM ${ }^{\circledast}$ functional fibrinogen, CT clotting time (s), CFT clot formation time (s), MCF maximum clot firmness (mm), MCE fibrinogen level $(\mathrm{g} / \mathrm{L}), A D$ hypoadrenocorticism, $A P L E$ acute protein losing enteropathy, $C H$ chylothorax, PLN protein losing nephropathy, CPLE protein losing enteropathy, ND not determined, italicize numbers indicate the hypercoagulable dogs at T0 $(\mathrm{N}=7)$ and are outside the institutional reference ranges. Institutional

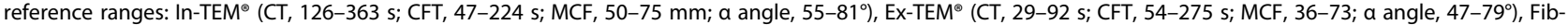
$\operatorname{TEM}^{\circledast}\left(\mathrm{CT}, 14-102 \mathrm{~s} ; \mathrm{MCF}, 6-26 ; \mathrm{a} \text { angle, } 40-78^{\circ}\right)^{14}$ and fibrinogen level (1.5-4.50 g/L)

is a well-established link between inflammation and coagulation, it might be possible that the inflammatory processes impaired activation of pro- and anti-coagulant factors, fibrinolysis, and induced abnormalities in platelets and endothelial components, but in our study we have not looked into markers for inflammation and antithrombin level [36].

Other hematological factors are known to influence the ROTEM analysis and may have affected our results. The CFT, $\alpha$ angle, and MCF can be influenced by some sample features such as platelet count, fibrinogen concentration, and Hct [23]. Our results have not found any statistically significant difference in platelet count and fibrinogen concentration, whereas a statistically significant reduction in Hct, after $24 \mathrm{~h}$ of infusion, was noted in both groups at T1. Hematocrit can affect ROTEM results, leading to a hypocoagulable tracing when Hct is increase or a hypercoagulable tracing when it is decreased [37, 38]. Smith et al. [37] hypothesized that a whole blood sample with a decreased Hct has a greater concentration of coagulation factors (the plasma to erythrocyte ratio changes in the ROTEM cup), leading to an artifactual hypercoagulability tracing when the blood is analyzed with ROTEM, and vice versa in case of increased Hct $[37,38]$. Although no statistically significant difference in variation of Hct between the two groups was found from T0 to T1, the trend toward hypercoagulability identified in group 2 could be partially explained by the lower Hct values reached in this group at T1 (T1: Group 1, 39\% and Group 2, 35\% of Hct).

Although the platelet count remained unchanged between T0 and T1 (group 2), authors hypothesized that an increase in platelet activity could have been present. Indeed, no alterations were identified in the fib-TEM ${ }^{\odot}$ profile, where platelet activity was inhibited. ROTEM is not a specific tool to evaluate platelet function, but $\mathrm{MCE}_{\text {platelet }}$ could be used to assess the contribution of platelets activity to clot elasticity, thus eliminating the influence of fibrinogen. However, no difference was identified between $\mathrm{T} 0$ and $\mathrm{T} 1$ in 
$\mathrm{MCE}_{\text {platelet, }}$ and then a platelet contribution to hypercoagulable trend could be excluded.

Our findings differ from those reported in previous in vitro and in vivo studies that evaluated the effects of HES 130/0.4 on hemostasis by means of viscoelastic techniques (ROTEM and ROTEG). In two in vitro studies, when whole blood samples were diluted with HES 130/0.4 (1:22, 1:9, 1:4), a hypocoagulable ROTEM tracing was found only at the highest dilution $(1: 4, \mathrm{mim}$ icking in vivo administration of $30 \mathrm{ml} / \mathrm{kg}$ ) [11, 14]. Whereas, an impairment of secondary hemostasis has been identified after 1:5.5 dilution (comparable to a fluid dose of $20 \mathrm{ml} / \mathrm{Kg}$ ) using ROTEG analysis [12]. The results of in vitro studies cannot be directly extrapolated to predict in vivo results, as the effect that a HES solution may have on hemostasis is largely determined by its in vivo pharmacokinetics [39].

Only three in vivo studies evaluating changes in hemostasis following HES 130/0.4 administration, are currently available in literature. One evaluated platelet function, whereas the other two assessed viscoelastic properties of whole blood [17, 18, 20]. Gauthier et al. [17] found a significant prolongation of aPTT and a hypocoagulable ROTEG after administration of HES 130/0.4 (bolus of $40 \mathrm{ml} / \mathrm{kg}$ over $30 \mathrm{~min}$ ) in healthy dogs and dogs with induced systemic inflammatory response syndrome [17]. Reutler et al. [20] detected by means of ROTEM an impairment of whole blood coagulation after administration of a single bolus of HES $(15 \mathrm{ml} / \mathrm{kg}$ over 30-40 min) in dogs undergoing general anesthesia for arthroscopy or imaging studies [20]. Comparison between our study and those mentioned above is difficult, because of the differences in study populations, rate and volume infused. The dogs in the present study were affected by naturally occurring diseases that cause hypoalbuminemia, whereas the sample populations in the other studies were healthy, anesthetized dogs or dogs with experimentally induced disease. In addition, the chosen method of HES administration, implied different infusion rate; during bolus the total amount of dose (15 or $40 \mathrm{ml} / \mathrm{kg}$ ) is infused over a short period of time, resulting in an increase in intravascular volume (especially in hemodynamically stable dogs) and a greater hemodilution as compared with the administration as a CRI, where the total volume (24 or $48 \mathrm{ml} / \mathrm{Kg}$ ) is equally divided over $24 \mathrm{~h}$. Moreover, different rates are associated with a diverse degree of tissue accumulation and elimination [5].

At the time of inclusion in this study, only $7 / 20$ dogs had a ROTEM tracing indicating hypercoagulability, and defined as a ROTEM profile with more than one parameter outside the institutional reference range. The fibrinogen level was normal at T0 and the $\mathrm{MCE}_{\text {platelet }}$ altered in 3 patients in the $\mathrm{NH}$ group. Differently in the $\mathrm{H}$ group, the fibrinogen level and the $\mathrm{MCE}_{\text {platelet }}$ were outside the upper range in $6 / 7$ and $7 / 7$ animals, respectively (Table 3). These results indicate an influence of the fibrinogen amount on the ROTEM tracing and an increase in the platelet aggregation, which can partially explain the hypercoagulbility detected at T0. In literature has been reported that an increase in platelet activity is associated with hypoalbuminemia in dogs with PLN [30, 40, 41]. Since there were no statistical significant differences from $\mathrm{T} 0$ to $\mathrm{T} 1$ in group $\mathrm{H}$ and group $\mathrm{NH}$, in ROTEM results and $\mathrm{MCE}_{\text {platelet, we can excluded the possibility that }}$ the hypercoagulability trend, seen at $\mathrm{T} 1$ in the group 2 , was affected by the hypercoagulable patients.

Using ROTEG analysis, recent studies in dogs affected by PLE and PLN have identified hypercoagulability in the majority of them [25-27]. Due to the differences in the studies populations and the criteria for assessing hypercoagulability, a comparison with our study is not possible [25-27]. Until today, no standardized definition of hypercoagulability by ROTEM analysis in dogs has been established, although the PROVETS guidelines were issued in the attempt to achieve conformity across studies using viscoelastic techniques [42]. As there is insufficient evidence to recommend a definition of hypercoagulability in companion animals, the definition is left to the authors' discretion [42].

An increased risk of thromboembolic events has been reported for dogs affected by PLN or PLE. The underlying cause of hypercoagulability remains incompletely understood; potentially involved mechanisms are loss of antithrombin and increased platelet aggregation [30, 40, 41]. Since we did not measure antithrombin activity, we are unable to determine its influence on our ROTEM results. Although multiple mechanisms have been involved in hypercoagulable state [31, 32], the incidence of thromboembolism dramatically increases when serum albumin concentration is less than $2.0-2.5 \mathrm{~g} / \mathrm{dL}$, in human patients with PLN [31, 32]. In contrast, veterinary studies have shown that hypercoagulability identified with ROTEM analysis does not appear to be correlated with hypoalbuminemia [25-27], and only a weak correlation between serum albumin concentration and antithrombin activity has been identified in hypercoagulable dogs, indicating that albumin level cannot reliably predict it [25-27, 43, 44]. These findings highlight that the prothrombotic state in dogs is not related only to hypoalbuminemia but to other abnormalities as well.

Refractometric evaluation was used to measure the TS concentration. Our results showed a statistically significant increase in TS after 24 h (T1) of HES 130/0.4 as a CRI at $2 \mathrm{ml} / \mathrm{kg} / \mathrm{h}$ (Group 2). Bumpus et al. [45] reported that after the addition of a large volume of hetastarch (after an in vitro dilution of 1:4 corresponding to in vivo $22 \mathrm{ml} / \mathrm{kg}$ ) the refractometer reading of TS increased [45]. Although the in vitro dosage administered in the 
aforementioned study differs from dosages used in the study herein, the higher dose of HES used in the group 2 may have interfered with the refractometric reading. Furthermore, the refractometer reading of HES 130/0.4 is $4.5 \mathrm{mg} / \mathrm{dl}$, the same as that of the products used in the study by Bumpus et al. [45].

This study has several limitations. The small sample size, limits the ability to generalize the results obtained. Moreover, the clinicians were not blinded to the HES doses administered, which could have introduced a bias. The study population included dogs with diverse diseases, which might have several degrees of inflammation and different effect on hemostasis. In addition, we did not have a control group without treatment or treated only with a CRI of isotonic crystalloids, to determine whether the changes in hemostasis could be consequent to the progression of disease/inflammation or also related to the crystalloid infusion. In this regard, because the total amount of 24-h administration of crystalloids solution was not recorded, the influence of this variable could not be assessed.

Further studies on larger samples of dogs with naturally occurring disease causing hypoalbuminemia are needed to create disease categories and take into account the amount of infused crystalloid.

The assessment of HES 130/0.4 pharmacokinetics in dog could allow understanding the amount of its accumulation and the rate of elimination, especially when the colloid is administered as a CRI. In this context it would be important to evaluate the risks and benefits associated with HES therapy and its efficacy in providing oncotic support.

Another important field of research is to investigate the prevalence of hypercoagulability in hypoalbuminemic dogs, to better understand the impact of the underlying disease on the prothrombotic state and to correctly identify which hypoalbuminemic dogs could really benefit from anticoagulant therapy. Finally, further research for investigate the contribution of platelet function to hypercoagulable state, by means specific tools such as the PFA-100 or platelet aggregometer, would be interesting.

\section{Conclusion}

Our findings suggest that CRI of HES 130/0.4 (1-2 $\mathrm{ml} / \mathrm{kg} / \mathrm{h}$ over $24 \mathrm{~h})$ does not cause hypocoagulability in hypoalbuminemic dogs. A trend toward hypercoagulability, probably related to the underlying disease and associated degree of inflammation, was noted in group 2 at T1. Although all dogs were hyoalbuminemic, only $7 / 20$ were hypercoagulable at T0, confirming the lack of correlation between albumin level and prothrombotic state.

\section{Abbreviations}

aPTT: Activated partial thromboplastin time; CFT: Clot formation time; COP: Colloid osmotic pressure; CRI: Constant rate infusion; CT: Clotting time; HES: Hydroxyethyl starch; MCE: Maximum clot elasticity; MCEplatelet: Platelets contribution to clot elasticity; MCF: Maximum clot firmness; PLE: Protein losing enteropathy; PLN: Protein losing nephropathy; PT: Prothrombin time; ROTEG: Thromboelastography; ROTEM: Thromboelastometery

\section{Acknowledgements}

The authors thank the technical staff and the students for their assistance.

\section{Funding}

This research had no funding sources.

\section{Availability of data and materials}

The datasets used and/or analysed during the current study are available from the corresponding author on reasonable request.

\section{Authors' contributions}

$A B$ and $B B$ contributed to the conception and design of the study. ABotto and $B B$ acquired the data. $A B$ interpreted the data. $A B, A B$ otto and $B B$ drafted the manuscript. CM performed the statistical analysis, AT, FR and GM contributed to the conception of the study, participated in its design and coordination, and helped to draft the manuscript. All authors read and approved the final manuscript.

\section{Ethics approval}

The protocol was approved by the Bioethics Committee of the Turin University. The dog owners were informed about the methods and purpose of the study and gave their written informed consent.

\section{Consent for publication}

Not applicable.

\section{Competing interests}

The authors declare that they have no competing interests.

\section{Publisher's Note}

Springer Nature remains neutral with regard to jurisdictional claims in published maps and institutional affiliations.

\section{Author details}

${ }^{1}$ Department of Veterinary Science, University of Turin, Largo Paolo Braccini $n$ ²-5, 10095 Grugliasco, TO, Italy. ${ }^{2}$ Istituto Zooprofilattico Sperimentale del Piemonte, Liguria e Valle d'Aosta, via Bologna 148, 10154 Torino, Italy. ${ }^{3}$ Department of Public Health and Pediatric Sciences, C.so Bramante 88/90, 10100 Torino, Italy.

Received: 27 June 2017 Accepted: 17 January 2018

Published online: 31 January 2018

\section{References}

1. Glover PA, Rudloff E, Kirby R. Hydroxyethyl starch: a review of pharmacokinetics, pharmacodynamics, current products, and potential clinical risks, benefits, and use. J Vet Emerg Crit Care. 2014;24(6):642-61.

2. Adamik K, Yozova ID, Regenscheit N. Controversies in the use of hydroxyethyl starch solution in small animal emergency and critical care. J Vet Emerg Crit Care. 2015;25(1):20-47.

3. DiBartola SP. Fluid theraphy with macromolecular plasma volueme expanders. 4rd ed. St Louis: Saunders Elsevier; 2012. p. 647-59.

4. Westphal M, James MF, Kozek-Langenecker S, et al. Hydroxyethyl starches: different products-different effects. Anesthesiology 2009;111(1):187-202.

5. Trieb J, Haass A, Pindur G, et al. HES 200/0.5 is not HES 200/0.5. Influence of the C2/C6 hydroxyethylation ratio of hydroxyethyl starch (HES) on hemorheology, coagulation and elimination kinetics. Thromb Haemost. 1995;74(6):1452-6.

6. Entholzner EK, Mielke $L L$, Calatzis AN, et al. Coagulation effects of a recently developed hydroxyethyl starch (HES 130/0.4) compared to hydroxyethyl starches with higher molecular weight. Acta Anaesthesiol Scand. 2000;44(9):1116-21.

7. Kozek-Langenecker SA. Effects of hydroxyethyl starch solutions on hemostasis. Anesthesiology. 2005;103(3):654-60. 
8. Wierenga JR, Jandrey KE, Haskins ST, Tablin F. In vitro comparison of the effects of two forms of hydroxyethyl starch solutions on platelet function in dogs. Am J Vet Res. 2007;68(6):605-9.

9. McBride D, Hosgood GL, Mansfield CS, Smart L. Effect of hydroxyethyl starch 130/0.4 and 200/0.5 solution on canine platelet function in vitro. Am J Vet Res. 2013;74(8):1133-7.

10. Classen J, Adamik KN, Weber K, Rubenbauer S, Hartmann K. In vitro effect of hydroxyethyl starch 130/0.42 on canine platelet function. Am J Vet Res. 2012;73(12):1908-12

11. Falco S, Bruno B, Maurella $C$, et al. In vitro evaluation of canine hemostasis following dilution with hydroxyethyl starch (130/0.4) via thromboelastometry. J Vet Emerg Crit Care. 2012;22(6):640-5.

12. Griego-Valles M, Buriko Y, Prittie JE, Fox PR. An in vitro comparison of the effects of voluven (6\% hydroxyethyl starch 130/0.4) and hespan (6\% hydroxyethyl starch 670/0.75) on measures of blood coagulation in canine blood. J Vet Emerg Crit Care. 2016;27(1):44-51.

13. Bacek LM, Martin LG, Spangler EA, Macintire DK. Determination of the in vitro effects of two forms of hydroxyethyl starch solutions on thromboelastography and coagulation parameters in healthydogs (Abstr). J Vet Emerg Crit Care. 2011;21(Suppl 1):26-7.

14. Wurlod VA, Howard J, Francey T, Schweighauser A, Adamik KN. Comparison of the in vitro effects of saline, hypertonic hydroxyethyl starch, hypertonic saline, and two forms of hydroxyethyl starch on whole blood coagulation and platelet. J Vet Emerg Crit Care. 2015;25(4):474-8.

15. Smart $L$, Jandrey $K E$, Kass $P H$, et al. The effect of hetastarch $(670 / 0.75)$ in vivo on platelet closure time in the dog. J Vet Emerg Crit Care. 2009;19(5):444-9.

16. Chohan AS, Greene SA, Grubb TL, et al. Effects of $6 \%$ hetastarch $(600 / 0.75)$ or lactated Ringer's solution on hemostatic variables and clinical bleeding in healthy dogs anesthetized for orthopedic surgery. Vet Anaesth Analg. 2011;38(2):94-105.

17. Gauthier V, Holowaychuk MK, Kerr CL, Bersenas AME, Darren Wood R. Effect of synthetic colloid administration on coagulation in healthy dogs and dogs with systematic inflammation. J Vet Intern Med. 2015;29(1):276-85.

18. McBride D, Hosgood G, Raisis A, Smart L. Platelet closure time in anesthetized greyhounds with hemorrhagic shock treated with hydroxyrthyl starch 130/0.4 or 0,9\% sodium chloride infusion. J Vet Emerg Crit Care. 2016; 26(4):509-15.

19. Helmbold KA, Mellema MS, Hoper K, Epstein SE. The effect of hetastarch $670 / 0.75$ administered in vivo as a constant rate infusion on platelet closure time. J Vet Emerg Crit Care. 2014;24(4):381-7.

20. Reutler A, Flammer SA, Howard J, Adamik KA. Comparison of the effects of a balanced crystalloid-based and saline based tetrastarch solution on canine whole blood coagulation and platelet function. J Vet Emerg Crit Care. 2017; 27(1):23-34.

21. Smith SA. The cell-based model of coagulation. J Vet Emerg Crit Care. 2009;19(1):3-10

22. Kol A, Borjesson DL. Application of thromboelastography/thromboelastometry to veterinary medicine. Vet Clin Pathol. 2010;39(4):405-16.

23. McMichael MA, Smith SA. Viscoelastic coagulation testing: technology, applications and limitations. Vet Clin Pathol. 2011:40(2):140-53.

24. Falco S, Zanatta R, Bruno B, et al. Thromboelastometry used for evaluation of blood coagulability in dogs with kidney diseases. Acta Vet Brno. 2013; 82(2):209-14.

25. Goodwin LV, Goggs DL, Chan DL, Allenspach K. Hypercoagulability in dogs with protein-losing enteropathy. J Vet Intern Med. 2011;25(2):273-7.

26. Lennon EM, Hanel RM, Walker JM, Vaden SL. Hypercoagulability in dogs with protein-losing nephropathy as a assessed by thromboelastography. J Vet Intern Med. 2013;27(3):462-8.

27. White CR, Langston C, Hohenhaus AE, Lamb K, Hackner S, Fox PR. Evaluation of the relationship between clinical variables and thromboelastographic findings in dogs with protein-losing nephropathy. Vet Emerg Crit Care. 2016;26(1):74-9.

28. Peterson PB, Willard MD. Protein-losing enteropathies. Vet Clin North Am Small Anim Pract. 2003;33(5):1061-82.

29. Vaden SL, Hammemberg B, Davenport DJ, et al. Food hypersensitivity reaction in soft coated wheaten terrier with protein-losing enteropathies or protein losing nephropathy or both: Gastroscopic food sensitivity testing, dietary provocation, and fecal immunoglobulin E. J Vet Int Med. 2000;14(1):60-7.

30. Cook AK, Cowgill LD. Clinical and pathological features of protein-losing glomerular disease in the dogs: a review of 137 cases(1985-1992). J Am Anim Hosp Assoc. 1996;32(4):313-22.
31. Twig G, Zandman-Goddard G, Szyper-Kravitz M, Shoenfeld Y. Systematic tromboembolism in inflammatory bowel disease: mechanisms and clinical application. Ann N Y Acad Sci. 2005;1051:166-73.

32. Huang MJ, Wei RB, Wang $Z$, et al. Mechanisms of hypercoagulability in nephrotic syndrome associated with membranous nephropathy as assessed by thromboelastography. Thromb Res. 2015;136(3):663-8.

33. Goggs R, Brainard B, de Laforcade AM, et al. Partnership on rotational viscoelastic test standardization (PROVETS): evidence-based guidelines on rotational viscoelastic assays in veterinary medicine. J Vet Emerg Crit Care. 2014;24(1):1-22

34. Flatlan B, Koenigshof AM, Rozanski EA, et al. Systematic evaluation of evidence on veterinary viscoelastic testing part 2: sample acquisition and handling. J Vet Emerg Crit Care. 2014;24(1):30-6.

35. Solomon C, Ranucci M, Hochleitner G, et al. Assessing the methodology for calculating platelet contribution to clot strength (platelet component) in Thromboelastometry and Thrombelastography. Anesth Analg. 2015;121(4):868-78.

36. De Laforcade A. Diseases associated with thrombosis. Top Companion Anim Med. 2012;27(2):59-64

37. Smith S, McMichael A, Gilor S, Galligan A, Hon C. Correlation of hematocrit, platelet concentration, and plasma coagulation factors with results of tromboelastometry in canine whole blood samples. Am J Vet Res. 2012; 73(6):789-98.

38. McMichael M, Smith SA, Galligan A, Swanson KS. In vitro hypercoagulability on whole blood thromboelastometry associated with in vivo reduction of circulating red cell mass in dogs. Vet Clin Pathol. 2014;43(2):154-63.

39. Treib J, Baron JF, Grauer MT, et al. An international view of hydroxyethyl starches. Intensive Care Med. 1999;25(3):258-68.

40. Green RA, Kabel AL. Hypercoagulable state in three dogs with nephrotic syndrome: role of acquired antithrombin III deficiency. J Am Vet Med Assoc. 1982;181(9):914-7.

41. Green RA, Russo EA, Greene RT, Kabel AL. Hypoalbuminemia - related platelet hypersensitivity in two dogs with nephrotic syndrome. J Am Vet Med Assoc. 1985:186(5):485-8.

42. Hanel RM, Chan DL, Conner B, et al. Systematic evaluation of evidence on veterinary viscoelastic testing part 4: definition and data reporting. J Vet Emerg Crit Care. 2014;24(1):47-56.

43. Kuzi S, Segev G, Haruvi E, Aroch I. Plasma antithrombin activity as a diagnostic and prognostic indicator in dogs: a retrospective study of 149 dogs. J Vet Intern Med. 2010;24(3):587-96.

44. Klosterman ES, Moore GE, de Brito Galvao JF, et al. Comparison of signalament, clinicopatholigic findings, histologic diagnosis, and prognosis in dogs with glomerular disease with or without nephrotic syndrome. J Vet Intern Med. 2011;25(2):206-14.

45. Bumpus SE, Haskins SC, Kass PH. Effects of synthetic colloids on refractometric readings of total solid. J Vet Emerg Crit Care. 1998;8(1):21-6.

\section{Submit your next manuscript to BioMed Central and we will help you at every step:}

- We accept pre-submission inquiries

- Our selector tool helps you to find the most relevant journal

- We provide round the clock customer support

- Convenient online submission

- Thorough peer review

- Inclusion in PubMed and all major indexing services

- Maximum visibility for your research

Submit your manuscript at www.biomedcentral.com/submit 